\title{
The Influence of Gender on the Cortical Width of the Lower Border of the Mandible and the Mandibular Cortical Index
}

\author{
Alma Kamber-Ćesir, Amela Dardagan Đonlagić, Muhamed Ajanović, Sanela Strujić \\ Porović, Alma Gavranović, Lejla Kazazić, Lejla Berhamović, Emir Berhamović
}

Prosthetic Department of the School of Dental Medicine, University of Sarajevo, Sarajevo, Bosnia and Herzegovina

Correspondence: almakamber@yahoo.com Tel.: + 38733407816

Fax.: + 38733443395

Received: 22 May 2018

Accepted: 3 October 2018

Key words: Mental Index - Mandibular Cortical Index $\cdot$ Gender.

\begin{abstract}
Objective. To evaluate the influence of gender on the mental index (MI) and the mandibular cortical index (MCI). Methods. In this study, there were 120 subjects (43 male and 77 female subjects), who had undergone a dental panoramic radiograph examination for the needs of diagnosis and future treatment planning. MI and MCI were determined by orthopantomograph. Results. There was a statistically significant difference in MI dependent on gender. Male patients demonstrated significantly higher values for MI than female patients (right: $\mathrm{t}=4.127 ; \mathrm{P}=0.0001$, left: $\mathrm{t}=3.110 ; \mathrm{P}=0.002$ ). No statistically significant difference was observed for MCI dependent on gender (right: $\chi^{2}=2.36 \mathrm{P}=0.308$, left: $\chi^{2}=3.85 \mathrm{P}=0.146$ ). Conclusion. $\mathrm{MI}$ is affected by gender, but MCI is not.
\end{abstract}

\section{Introduction}

The cortical thickness of the lower border of the mandible is a useful parameter for assessment of the bone quality of the mandible. Since the cortical thickness of the lower border of the mandible may be easily seen on a panoramic radiograph, with no need for specialized facilities, it is the index most-commonly used $(1,2)$. The cortical width below the mental foramen (mental index) (MI), at the gonion (gonion index) and antegonion (antegonion index) have often been measured. There is a relationship between these parameters and bone mineral density (3-6). The reproducibility and repeatability of digital panoramic images have been found to be high for measurements of MI (7).

The mandibular cortical index (MCI) has been used to assess the status of the man- dibular bone and to determine signs of resorption. Some authors have found that the mandibular cortical index makes it possible to identify reduced bone mineral density and to distinguish normal and osteoporotic bones (8-10). The MCI is based on Klemetti's classification of changes in the inferior cortex of the mandible on panoramic imaging (11). In postmenopausal women, the MCI was found to be significantly correlated with maxillary and mandibular bone mineral density (12). Von Wowern found that the average bone mineral content (BMC) loss (\%) in the bones of the mandible seems to be higher in older women (1.5 and $1.4 \%$ per year) than in older men (0.9 and $0.7 \%$ per year) (13). Thus, it seems important to monitor the sex- and age-related bone mineral content loss in the mandible separately. The results of bone mineral content exami- 
nations indicated a significant difference between the two sexes. With advancing age, the values of BMC measured in male mandibles tended to increase slightly, and in female the mandibles tended to decrease (14).

The aim of this study was to evaluate the influence of gender on MI and MCI.

\section{Methods}

\section{Subjects}

In this study, there were 120 subjects (43 male and 77 female subjects), with an age range from 21 to 80 years, who had undergone a dental panoramic radiograph examination for the needs of diagnosis and future treatment planning. The purpose of the research was presented to all the participants, and they provided written consent. The research was conducted at the Prosthetic Department of the School of Dental Medicine, University of Sarajevo.

Inclusion criteria were: subjects aged 21 years or above, who underwent a dental panoramic radiograph examination for the needs of diagnosis and future treatment planning, and the inferior mandibular cortex and both mental foramina should be noticeable on the radiograph. Exclusion criteria were: the presence of systemic disorders which affect bone mineral density, metabolic bone diseases, cancer with bone metastasis, use of medications that affect bone metabolism (corticosteroid, heparin, calcium, calcitonin, vitamin $\mathrm{D}$, bisphosphonates).

\section{Methods}

Dental panoramic radiographs were made using an Orthopantomograph OP 100. The same cephalostat was used during exposure, so that the Frankfurt horizontal plane (tragion-orbitale) was parallel to the horizontal plane, and the mediosagittal plane was per- pendicular to the horizontal plane. All films were processed in an automatic dark chamber processor (XR 24 Nova, Dürr Dental) for 7 minutes. Images were processed using Kodak film. The dental panoramic radiographs were viewed using a flat view box, in a room with subdued light.

Two examiners assessed indices on all dental panoramic radiographs. The cortical thickness below the mental foramen (MI) was measured on each radiograph on the right and left sides of the mandible (15): We drew a line parallel to the long axis of the mandible and tangential to the inferior border of the mandible, and constructed a dotted line perpendicular to this tangent intersecting the inferior border of the mental foramen, along which the mandibular cortical width was measured. The distance between the two parallel solid lines is the cortical width. Measurements of mental index were made using a magnifying loupe (x4, Gethaldus, Zageb, Croatia) and precise digital calliper, to precision of a $0.01 \mathrm{~mm}$ (version 05/09, model No. 1112-150, Conrad Electronic International, Germany). The mandibular cortical shape was determined on the dental panoramic radiographs by observing the mandible distally from the mental foramen bilaterally, according to the method of Klemetti et al. (11) as follows: C1- normal cortex, the endosteal margin of the cortex is even and sharp on both sides, C2- mildly to moderately eroded cortex, the endosteal margin shows semilunar defects (lacunar resorption) or appears to form endosteal cortical residues on one or both sides, C3- severely eroded cortex, the cortical layer forms heavy endosteal cortical residues and is clearly porous. The results demonstrated good intra-observer $(\mathrm{r}=0.86$ on the right side, $\mathrm{r}=0.95$ on the left side; $\mathrm{P}<0.01)$ and inter-observer correlations $(\mathrm{r}=0.81$ on the right side, $\mathrm{r}=0.86$ on the left side; $\mathrm{P}<0.01$ ). 


\section{Ethics Statement}

The study was approved by the Ethical Committee of the Faculty of Dentistry, University of Sarajevo, Bosnia and Herzegovina.

\section{Statistical Analysis}

The data were analysed using the SPSS 13.0 (IBM Co., NY, USA) statistical package. Categorical variables (sex and MCI) were presented as numbers and proportions (\%). Quantitative variables were presented as means and standard deviations (SD). Differences between groups for categorical variables were evaluated using the $\chi^{2}$ test. Differences for quantitative variables were evaluated using the student's $t$ test. $P$ values less than 0.05 were considered statistically significant. The normality of the variance distribution was verified using the Kolmogorov-Smirnov test. The one-sample Kolmogorov-Smirnov test revealed that all the variables of MI on both sides were distributed normally.

\section{Results}

One hundred and twenty subjects participated in this study aged from 21 to 80 years (46.83 \pm 15.96 years). According to dental status, there were 42 subjects who had all their teeth, 38 subjects who were partially dentate (Kennedy Class I) and without antagonistic contacts in the posterior regions, and 40 subjects who were completely edentulous. According to gender, there were more female subjects (77 subjects, 64.2\%) than male subjects (43 subjects, $35.8 \%$ ). The mean and standard deviation of the MI on both sides are presented in Table 1. The mean MI value measured on the right side was higher than MI measured on left side of the mandible, but there was no statistically significant difference.
Table 1. Values of Mental Index on Different Sides of the Mandible

\begin{tabular}{lllll}
\hline MI & $\bar{x}+S D$ & $\mathrm{Cl}(95 \%)$ & Min. & Max. \\
\hline Right & $4.42 \pm 0.91$ & $4.25-4.58$ & 2.19 & 7.05 \\
\hline Left & $4.36 \pm 0.91$ & $4.19-4.52$ & 2.14 & 6.75 \\
\hline
\end{tabular}

$\mathrm{MI}=$ Mental Index; $\mathrm{t}=1.032 ; \mathrm{P}=0.304$.

The mean and standard deviation of the $\mathrm{MI}$ according to gender are presented in $\mathrm{Ta}$ ble 2. Considering gender, the mean MI values were lower in females than in males on both sides of the mandible. The t-test demonstrated a statistically significant difference for MI between the gender groups.

Table 2. Difference for the Mental Index Between Gender Groups

\begin{tabular}{lll}
\hline \multirow{2}{*}{ Gender } & Right $^{*}$ & Left $^{\dagger}$ \\
\cline { 2 - 3 } & $\overline{\mathrm{x}} \pm \mathrm{SD}$ & $\overline{\mathrm{x}} \pm \mathrm{SD}$ \\
\hline Male $(\mathrm{N}=43)$ & $4.85 \pm 1.01$ & $4.69 \pm 1.02$ \\
\hline Female $(\mathrm{N}=77)$ & $4.18 \pm 0.75$ & $4.17 \pm 0.79$ \\
\hline Total $(\mathrm{N}=120)$ & $4.42 \pm 0.91$ & $4.36 \pm 0.91$ \\
\hline
\end{tabular}

$\mathrm{Ml}=$ Mental Index; ${ }^{\mathrm{t}} \mathrm{t}=4.127 ; \mathrm{P}<0.00 ;{ }^{\mathrm{t}} \mathrm{t}=3.110 ; \mathrm{P}=0.002$ on the left side.

The distribution of categories of MCI according to gender on both sides are presented in Table 3.

Table 3 Distribution of Categories of $\mathrm{MCl}$ According to Gender

\begin{tabular}{|c|c|c|c|c|}
\hline \multirow{4}{*}{ Categories } & \multicolumn{4}{|l|}{ Gender } \\
\hline & Male & Female & Male & Female \\
\hline & \multicolumn{2}{|l|}{ *Right } & \multicolumn{2}{|l|}{ Left $^{+}$} \\
\hline & $\mathrm{N}(\%)$ & $\mathrm{N}(\%)$ & $\mathrm{N}(\%)$ & $\mathrm{N}(\%)$ \\
\hline C1 & $8(18.6)$ & $19(24.7)$ & $6(14.0)$ & 23 (29.9) \\
\hline C2 & $29(67.4)$ & $41(53.2)$ & $28(65.1)$ & 40 (51.9) \\
\hline C3 & $6(14.0)$ & $17(22.1)$ & $9(20.9)$ & 14 (18.2) \\
\hline
\end{tabular}

$\mathrm{MCl}=$ Mandibular Cortical Index; $\mathrm{C} 1=$ Normal cortex; $\mathrm{C} 2=$ Mildly to moderately eroded cortex; $C 3=$ Severely eroded cortex; ${ }^{2}{ }^{2}=2.36$, $\mathrm{P}=0.308 ;{ }^{\top} \mathrm{X}^{2}=3.85, \mathrm{P}=0.146$.

The distribution of categories of $\mathrm{MCl}(\mathrm{C} 1, \mathrm{C} 2, \mathrm{C} 3)$ according to gender is similar. On the right side, most participants presented as $C 2$, and also on the left side. Differences for MCl between the gender groups are not statistically significant for the right side and the left side. 


\section{Discussion}

In the present study, the MCI and cortical width were used for assessment of the bone quality of the mandible. In recent decades many authors have investigated the relationship between these indices and different factors (systemic and local) such as age, gender, number of teeth, hormonal status (menopause) etc. The majority of studies on the MCI and cortical width have considered only the elderly female population, with or without signs of systemic osteoporosis. Our study group represented a typical range of female and male patients with a need for prosthodontics or periodontal treatment, with an age range of 21 to 80 years.

None of measurements taken in this study were corrected for the magnification inherent in panoramic radiography. All the radiographs were produced using the same type of panoramic equipment with a nominal magnification factor of 1.2. The results of our study revealed significant differences between males and females $(\mathrm{P}<0.001)$ in the measured values of the cortical width of the lower border of the mandible - below the MI. The females demonstrated lower values of MI measurements than the males. This finding is in agreement with the study of Musa et al. (16), who measured values of cortical width in participants aged 15 to 87 years. In Knezović-Zlatarić's study (17), MI showed a general downward trend for both genders with age until 75 years, when the mean values began to fall sharply for females compared to males, but the difference between the gender groups did not reach a statistically significant level for MI. Dutra et al. (18) found that MI values were significantly lower in older females, whereas they were greater in older males. Knezović-Zlatarić et al. (1) found that there was no significant difference in any linear radiomorphometric indices between boys and girls younger than 18 years. This could be attributed to the fact that this study group represented a typical range of young boys and girls, with no signs of any hormonal dysbalance. The influence of different sex-hormone metabolisms on bone structure and bone quality in those subjects had not yet reached the level of significance (1). Hastar et al. (19) found that there was a statistically significant difference in the measured MI between males and females older than 60 years. Yüzügüllü et al. (20) concluded that severe erosion of the endosteal margin of the mandible was seen more frequently in women over 60 years in age. While the mean mandibular cortical width values were stable in men over 60 years, the mean mandibular cortical width values decreased significantly in women of the same age group (20). The results of Kalinowski's study (21) showed that when age and gender were discussed simultaneously, the highest values of MI were observed in the 30-39 years age group in both genders, followed by a gradual decrease with age, but this decrease was more pronounced in females. The possible difference between males and females for MCI ratio could be explained by occlusal forces, because men have greater occlusal force than women (22-24). Al-Dwairi et al. found a positive correlation between MCI ratio and occlusal forces, so they reported that the average occlusal force in subjects with Klemetti class 3 was less than occlusal force in Klemetti class 1 subjects (25).

In evaluation of MCI on both sides of the mandible, the majority of males and females presented as C2. We found no significant difference for MCI between males and females.

Uysal et al. concluded that when the effects of age and gender are evaluated together, women may be expected to have a more porous mandibular cortex (26). Also, many authors found that MCI was affected by gen$\operatorname{der}(17,19,26,27)$. They found significantly more $\mathrm{C} 2$ and $\mathrm{C} 3$ in women than in men. In 
contrast, Gulsahi et al. concluded that MCI was not affected by gender (28).

\section{Conclusion}

The cortical thickness of the lower border of the mandible below the mental foramen, and the mandibular cortical index are important and simple indices for assessment of the bone quality of the mandible. No significant difference was found between the right and the left sides of the mandible for MI ( $\mathrm{P}>0.05)$. MI is affected by gender. Male patients demonstrated significantly higher values for MI than females. The mandibular cortical index is not affected by gender.

\section{What is already known on this topic}

The mandibular cortical index (MCI) and cortical width are indices for assessment of the status of the mandibular bone and for determining signs of resorption. They are important due to the relationship between these indices and bone mineral density. With advancing age, the cortex of the lower border of the mandible in women becomes thinner and more porous.

\section{What this study adds}

This study did not detect any difference between the right and the left sides of the mandible in terms of the cortical width of the mandible. Previous studies on the mandibular cortical index (MCI) and cortical width have mainly taken an elderly female population into consideration. This study included participants of both genders, with an age range of 21 to 80 years.

Authors' contributions: Conception and design: AKĆ and MA; Acquisition, analysis and interpretation of data: AKĆ, ADĐ, AG and MA; Drafting the article: AG and SSP; Revising it critically for important intellectual content: SSP, LB, LK and EB; Approved final version of the manuscript: AKĆ and ADĐ.

Conflict of interest: The authors declare that they have no conflict of interest.

\section{References}

1. Knezović Zlatarić D, Meštrović S, Kostelac D. The Comparison of Cortical Thickness of the Lower Border of the Mandible in Three Malocclusion Groups Dependent on Age and Gender. Acta Stomatol Croat. 2006;40(2):116-25.
2. Park HJ, Jung $\mathrm{YH}$, Cho BH. Bone changes after bilateral sagittal split osteotomy for mandibular prognathism. Korean J Oral Maxillofac Radiol. 2006;36(4):183-8.

3. Knezović Zlatarić D, Pandurić J, Korč M, Dodig D. Assessment tools in early detection of osteoporosis in dentistry. Arh Hig Rada Toksikol. 2007;58(1):33-9.

4. Miliuniene E, Alekna V, Peciuliene V, Tamulaitiene M, Maneliene R. Relationship between mandibular cortical bone height and bone mineral density of lumbar spine. Baltic Dent Maxillofac J. 2008;10(2):72-5.

5. Taguchi A. Panoramic radiographs for identifying individuals with undetected osteoporosis. Jpn Dent Sci Rev. 2009;45(2):109-20.

6. Gaur B, Chaudhary A, Wanjari PV, Sunil MK, Basavaraj P. Evaluation of panoramic Radiographs as a Screening Tool of Osteoporosis in Post Menopausal Women: A Cross Sectional Study. J Clin Diagn Res. 2013;7(9):2051-5.

7. Toraman AM, Peker İ, Şanal Ö. Assessment of repeatability and reproducibility of mental and panoramic mandibular indices on digital panoramic images. Int Dent J. 2007;57(6):433-8.

8. Balcikonyte E, Balciuniene I, Alekna V. Panoramic radiographs in assessment of the bone mineral density. Baltic Dent Maxillofac J. 2004;6:17-9.

9. Halling A, Persson GR, Berglund J, Johansson O, Renvert S. Comparison between the Klemetti index and heel DXA BMD measurements in the diagnosis of reduced skeletal bone mineral density in the elderly. Osteoporos Int. 2005;16(8):9991003.

10. Nalçaci R, Baran İ, Orkun S, Tosun A, Misirlioğlu M. Evaluation of panoramic radiography measures for identifying reduced bone mineral density in elderly. Turk J Geriatrics. 2010;13(1):18-25.

11. Klemetti E, Kolmakov S, Kroger H. Pantomography in assessment of the osteoporosis risk group. Scand J Dent Res. 1994;102(1):68-72.

12. Igarashi Y, Takamori H, Yoshue T. The Correlation between the Mandibular Cortical Parameters on Panoramic Radiographs and the Bone Densities of Jaw and Skeletal Bones. Nippon Koku Inpuranto Gakkaishi. 2006;19(1):3-13.

13. Von Wowern N. Bone mineral content of mandibles: normal reference values--rate of age-related bone loss. Calcif Tissue Int. 1988;43(4):193-8.

14. Ulm CW, Solar P, Ulm MR, Matejka M. Sex-related changes in the bone mineral content of atrophic mandibles. Calcif Tissue Int. 1994;54(3):203-7.

15. Ledgerton D, Horner K, Devlin H, Worthington $\mathrm{H}$. Panoramic mandibular index as a radiomor- 
phometric tool: an assessment of precision. Dentomaxillofac Radiol. 1997;26(2):95-100.

16. Musa I, Knezović-Zlatarić D, Čelebić A, Bošnjak A. The Influence of Gender and Age on the Values of Linear Radiomorphometric Indices Measured on the Lower Border of the Mandible. Acta Stomat Croat. 2002;36(2):191-7.

17. Knezović Zlatarić D, Čelebić A, Lazić B, Baučić I, Komar D, Stipetić-Ovčariček J, et al. Influence of age and gender on radiomorphometric indices of the mandible in removable denture wearers. Coll Antropol. 2002;26(1):259-66.

18. Dutra V, Yang J, Devlin H, Susin C. Radiomorphometric indices and their relation to gender, age, and dental status. Oral Surg Oral Med Oral Pathol Oral Radiol Endod. 2005;99(4):479-84.

19. Hastar E, Yilmaz HH, Orhan H. Evaluation of mental index, mandibular cortical index and panoramic mandibular index on dental panoramic radiographs in the elderly. Eur J Dent. 2011;5(1):607.

20. Yüzügüllü B, Gulsahi A, Imirzalioglu P. Radiomorphometric indices and their relation to alveolar bone loss in completely edentulous Turkish patients: a retrospective study. J Prosthet Dent. 2009;101(3):160-5.

21. Kalinowski P, Różyło-Kalinowska I. Mandibular inferior cortex width may serve as a prognostic osteoporosis index in Polish patients. Folia Morphol. 2011;70(4):272-81.
22. Bonakdarchian M, Askari N, Askari M. Effect of face form on maximal molar bite force with natural dentition. Arch Oral Biol. 2009;54(3):201-4.

23. Regalo SCH, Santos CM, Vitti M, Regalo CA, Vasconcelos PB, Mastriner J, et al. Evaluation of molar and incisor bite force in indigenous compared with white population in Brazil. Arch Oral Biol. 2008;53(3):282-6.

24. Duygu KOÇ, Doğan A, Bülent B. Effect of gender, facial dimensions, body mass index and type of functional occlusion on bite force. J Appl Oral Sci. 2011;19(3):274-9.

25. Al-Dwairi ZN, Al-Daqaq ANF, Kielbassa AM, Lynch E. Association between oral tori, occlusal force, and mandibular cortical index. Quintessence Int. 2017;48(10):841-9.

26. Uysal S, Çağırankaya BL, Hatipoğlu MG. Do gender and torus mandibularis affect mandibular cortical index? A cross-sectional study. Head Face Med. 2007;3(1):37-47.

27. Kiswanjaya B, Yoshihara A, Deguchi T, Hanada N, Miyazaki H. Relationship between the mandibular inferior cortex and bone stiffness in elderly Japanese people. Osteoporos Int. 2010;21(3):4338.

28. Gulsahi A, Özden Ş, Cebeci İA, Kucuk NO, Paksoy $\mathrm{CS}$, Genc Y. The relationship between panoramic radiomorphometric indices and the femoral bone mineral density of edentulous patients. Oral Radiol. 2009;25(1):47-52. 